Ricina e a Convenção para Proibição de Armas Químicas no Brasil

\author{
Sousa, R. B.; Oliveira, S. E. M.; Santos, M. C.; Lima, K.S.C.; Lima, A. L. S.* \\ Rev. Virtual Quim., 2014, 6 (3), 744-760. Data de publicação na Web: 11 de março de 2014 \\ http://www.uff.br/rvq
}

\title{
Ricin and the Chemical Weapons Convention in Brazil
}

\begin{abstract}
This article presents a brief review of the literature on ricin. This toxin is considered as a case of vulnerability in Brazilian responsibilities related to The Chemical Weapons Convention (CWC). Ricin is a glycoprotein present in seeds of castor beans (Ricinus communis $L$ ). It is very lethal and considered a chemical weapon. Brazil is the third world place in production of castor beans. Tons of residues with high quantities of ricin are produced every year. In this paper, examples of the ricin in terrorist attacks are remembered. It also mentions aspects on the action mechanism in the human body. The importance of the fast detection and identification is emphasized with description of methods used by first emergency responders and specialized chemical laboratories. Ricin detoxification has military interest and also may aggregate value to castor beans residues. At last, there is a brief on vaccines development against ricin.
\end{abstract}

Keywords: Ricin; castor beans; chemical weapons; OPCW.

\section{Resumo}

Este artigo apresenta uma mini-revisão da literatura sobre a ricina, abordando a vulnerabilidade que essa toxina representa para o Brasil em relação à Convenção para Proibição de Armas Químicas (CPAQ). A ricina é uma glicoproteína presente na mamoneira (Ricinus communis L.), planta endêmica no território brasileiro. Devido a sua elevada toxicidade é considerada uma arma química. O Brasil é o terceiro maior produtor mundial de mamona, gerando todos os anos toneladas de resíduos contendo alto teor de ricina. Esse trabalho aborda aspectos do mecanismo de ação dessa substância no organismo além de citar casos da literatura internacional sobre o uso dessa substância em ações terroristas. A importância de métodos de detecção e de identificação rápidos e confiáveis é enfatizada com descrição de técnicas utilizadas tanto por equipes de resposta a emergências, quanto por laboratórios de química especializados. Os processos de destoxificação de ricina, além de possuírem importância militar, podem agregar valor econômico aos resíduos da agroindústria mamoneira. Por fim, é abordado o desenvolvimento de vacinas para imunização contra o envenenamento por ricina.

Palavras-chave: Ricina; mamona; armas químicas; OPAQ.

\footnotetext{
* Instituto Militar de Engenharia, Seção de Engenharia Química, Praça General Tibúrcio 80, CEP 22290270, Rio de Janeiro-RJ, Brasil.

Msantoslima@ime.eb.br DOI: $\underline{10.5935 / 1984-6835.20140045}$
} 


\title{
Ricina e a Convenção para Proibição de Armas Químicas no Brasil
}

\author{
Roberto B. Sousa, Sérgio Eduardo M. de Oliveira, Marcelo C. dos Santos, \\ Keila S. C. Lima, Antônio Luiz S. Lima* \\ Instituto Militar de Engenharia, Seção de Engenharia Química, Praça General Tibúrcio 80, CEP \\ 22290-270, Rio de Janeiro-RJ, Brasil. \\ * santoslima@ime.eb.br
}

Recebido em 11 de março de 2014. Aceito para publicação em 11 de março de 2014

1. O Brasil e a Convenção para Proibição de Armas Químicas (CPAQ)

2. A Ricina e a agroindústria da mamona

3. Extração de ricina a partir de mamona

4. Estrutura e mecanismo de ação da ricina

5. Uso de ricina como arma química

6. Detecção e identificação de ricina

7. Descontaminação

8. Destoxificação

9. Antídotos e vacinas

10. Conclusões

\section{O Brasil e a Convenção para Proibição de Armas Químicas (CPAQ)}

Em 2013, a Organização para a Proibição de Armas Químicas (OPAQ) ${ }^{1}$ foi laureada com o Prêmio Nobel da Paz, em reconhecimento aos seus esforços para eliminar armas químicas no mundo. ${ }^{2} \mathrm{~A} \mathrm{OPAQ}^{1}$ é responsável pela implementação da Convenção sobre a Proibição do Desenvolvimento, Produção, Estocagem e Uso de Armas Químicas e sobre a Destruição das Armas Químicas Existentes no Mundo, comumente chamada de Convenção para Proibição de Armas Químicas (CPAQ). ${ }^{3}$ O Brasil assinou a convenção em 1993 e exerceu papel de destaque na criação da OPAQ, ${ }^{1}$ tendo sido o primeiro país a assumir a Direção-Geral da organização em 1997, após a escolha do brasileiro José Mauricio Bustani para o cargo. ${ }^{4}$

O Congresso Nacional ratificou a assinatura da $\mathrm{CPAQ}^{3}$ em 1996 e a Presidência da República promulgou a execução e cumprimento da convenção em 1999, incorporando-a ao conjunto das leis brasileiras. ${ }^{5,6}$ 
A CPAQ $^{3}$ apresenta três definições diferentes e complementares para armas químicas, abordando substâncias químicas, munições e dispositivos. Considerando apenas a primeira, armas químicas são "substâncias químicas tóxicas ou seus precursores, com exceção das que forem destinadas para fins não proibidos por esta Convenção, desde que os tipos e as quantidades em questão sejam compatíveis com esses fins" ${ }^{\prime 3,5,6}$. As definições de "substâncias químicas tóxicas e seus precursores" são bastante amplas e genéricas, evitando-se uma lista limitada e definitiva de substâncias.

As substâncias químicas controladas pela convenção são relacionadas nas Tabelas 1, 2 e 3 do Anexo sobre Substâncias Químicas da CPAQ. ${ }^{3}$ As tabelas são divididas em Parte $A$ (produtos químicos tóxicos) e $B$ (precursores). Quanto menor o número da tabela, maior é o risco oferecido pela substância e menor é a possibilidade de ela ser usada para fins pacíficos. É importante observar que a legislação não proíbe o uso pacífico das substâncias tabeladas, sendo permitidas atividades industriais, agrícolas, de pesquisas e outras, desde que respeitadas as exigências dos limites quantitativos previstos. $^{3}$ As Tabelas 1,2 e 3 deste trabalho apresentam as substâncias constantes das respectivas tabelas 1,2 e 3 da convenção. As estruturas de algumas dessas moléculas são mostradas na Figura 1.

Algumas das substâncias relacionadas nas tabelas da $\mathrm{CPAQ}^{3}$ são produzidas industrialmente em larga escala no Brasil, principalmente nos polos químicos de São Paulo, Rio de Janeiro e Salvador. ${ }^{7-9}$ Dentre elas, encontram-se a trietanolamina, o tricloreto de fósforo, o fosgênio e outras. ${ }^{7-9} \mathrm{~A}$ trietanolamina, por exemplo, é amplamente utilizada em inúmeras aplicações pacíficas. Contudo, sua produção necessita ser controlada por se tratar de um precursor essencial para a síntese de agentes químicos de guerra conhecidos como mostardas nitrogenadas. ${ }^{10}$

Indústrias produtoras de compostos orgânicos discretos (DOC) ou contendo átomos de fósforo, enxofre e flúor (PSF) também estão sujeitas aos mecanismos de controle da CPAQ. ${ }^{3}$ De acordo com o relatório anual da OPAQ de 2011, o Brasil declarou possuir naquele ano mais de noventa plantas industriais produzindo DOC e PSF. ${ }^{11}$ Além disso, o país declarou também que seis indústrias brasileiras produzem substâncias da Tabela 2 e que sete produzem compostos da Tabela $3 .{ }^{11}$ Com o objetivo de garantir que toda a produção dessas indústrias seja destinada a finalidades pacíficas, elas estão sujeitas a mecanismos de controle das autoridades brasileiras e recebem também constantes inspeções da OPAQ. ${ }^{1}$

Por outro lado, além da possibilidade de uso indevido de substâncias produzidas industrialmente, há outro grande risco aos objetivos da CPAQ no Brasil. Esse risco está associado à ricina, uma das duas biotoxinas relacionadas na Tabela 1 da $\mathrm{CPAQ}^{3}$ A ricina pode ser extraída de sementes de mamona e o acesso relativamente fácil a essa toxina representa uma vulnerabilidade do país nessa área.

\section{A Ricina e a agroindústria da mamona}

A ricina é uma glicoproteína de elevada toxidez presente nas sementes da mamoneira (Ricinus communis L.), planta endêmica no território brasileiro. ${ }^{12-15}$ Estimase que a dose letal $\left(L_{50}\right)$ em humanos esteja na faixa de 5-10 $\mu \mathrm{g} \cdot \mathrm{kg}^{-1}$ por inalação e 1-20 mg. $\mathrm{kg}^{-1}$ por ingestão oral. ${ }^{14}$

A Figura 2 ilustra uma amostra de mamonas colhidas em um terreno sem cultivo em área urbana na cidade de Colatina-ES (coordenadas geográficas: lat. 19.505472; long. -40.616072). Além do crescimento natural da planta em todas as regiões do território brasileiro, ocorre também o cultivo para fins comerciais. 0 Brasil é o terceiro maior produtor mundial de óleo de mamona, utilizado na produção de lubrificantes, combustíveis, fármacos e em outras aplicações. ${ }^{15}$ De acordo com o Censo 
Agropecuário 2006 do Instituto Brasileiro de Geografia e Estatística (IBGE), o Brasil possuía naquele ano mais de 23 mil estabelecimentos trabalhando com o plantio de mamona. ${ }^{16}$ Os dados do censo mostraram uma produção de quase 62 mil toneladas de mamona, colhidas de uma área total de mais de $110 \mathrm{mil}$ hectares. A região nordeste é responsável pela maior parte dessa produção, conforme ilustrado na Figura $3 .^{16} \mathrm{Em}$ termos econômicos, o valor total da produção brasileira foi de $\mathrm{R} \$ 31.496 .000,00 .^{16}$

A produção de 1,0 ton. de óleo de mamona gera aproximadamente 1,2 ton. de resíduo rico em ricina, conhecido como "torta de mamona". ${ }^{17,18} \mathrm{~A}$ literatura reporta uma grande variação nos teores de ricina presente na torta de mamona. Enquanto Oliveira e colaboradores encontraram o valor médio de $799 \mathrm{mg}$ de ricina para cada kg de torta de mamona, Anandan e colaboradores calcularam o teor em $388 \mathrm{mg} / \mathrm{kg} .{ }^{17,18}$ Cabe ressaltar que foram usadas diferentes matérias-primas e diferentes métodos de análise nos estudos de cada grupo. Apesar da aparente divergência de valores, ambos os resultados indicam que os resíduos gerados anualmente pela agroindústria mamoneira no Brasil contêm toneladas do agente químico de guerra ricina em sua composição.

Tabela 1. Substâncias relacionadas na Tabela 1 do anexo sobre substâncias químicas da $\mathrm{CPAQ}^{3}$

\section{Parte A: Substâncias químicas tóxicas}

1) Alquil (metil, etil, $n$-propil ou isopropil) fosfonofluoridratos de O-alquila ( $\leq \mathrm{C} 10$, incluindo cicloalquila).

Exemplos:

- Sarin (metilfosfonofluoridrato de O-isopropila); CAS 107-44-8.

- Soman (metilfosfonofluoridrato de O-pinacolila); CAS 96-64-0.

2) N,N-dialquil (metil, etil, $n$-propil ou isopropil) fosforamidocianidatos de O-alquila ( $\leq \mathrm{C} 10$, incluindo cicloalquila).

Exemplo: Tabun (N,N-dimetilfosforamidocianidato de O-etila); CAS 77-81-6.

3) S-2 dialquil (metil, etil, $n$-propil ou isopropil) aminoetilalquil (metil, etil, $n$-propil ou isopropil) fosfonotiolatos de $\mathrm{O}$-alquila ( $\mathrm{H}$ ou $\leq \mathrm{C} 10$, incluindo cicloalquila) e sais alquilados ou protonados correspondentes.

Exemplo: VX (S-2-di-isopropilaminoetilmetilfosfonotiolato de etila); CAS 50782-69-9.

4) Mostardas de enxofre

- Clorometilsulfeto de 2-cloroetila; CAS 2625-76-5.

- Gás mostarda: sulfeto de bis(2-cloroetila); CAS 505-60-2.

- Bis(2-cloroetiltio)metano; CAS 63869-13-6.

- Sesquimostarda: 1,2-bis(2-cloroetiltio)etano; CAS 3563-36-8.

- 1,3-bis(2-cloroetiltio)-n-propano; CAS 63905-10-2.

- 1,4-bis(2-cloroetiltio)- $n$-butano; CAS 142868-93-7.

- 1,5-bis(2-cloroetiltio)-n-pentano; CAS 142868-94-8.

- Bis(2-cloroetiltiometil) éter; CAS 63918-90-1.

- Mostarda O: bis(2-cloroetiltioetil) éter; 63918-89-8.

\section{5) Levisitas}

- Levisita 1: 2-clorovinildicloroarsina; CAS 541-25-3.

- Levisita 2: bis (2-clorovinil) cloroarsina; CAS 40334-69-8. 
- Levisita 3: tris (2-clorovinil) arsina; CAS 40334-70-1.

6) Mostardas de nitrogênio

- HN1: bis (2-cloroetil) etilamina; CAS 538-07-8.

- HN2: bis (2-cloroetil) metilamina; CAS 51-75-2.

- HN3: tris (2-cloroetil) amina; CAS 555-77-1.

7) Saxitoxina; CAS 35523-89-8

8) Ricina; CAS 9099-86-3.

Parte B: Precursores de substâncias químicas tóxicas

9) Fosfonildifluoretos de alquila (metil, etil, $n$-propil ou isopropil)

Exemplo: DF (metilfosfonildifluoreto); CAS 676-99-3.

10) O-2-dialquil (metil, etil, $n$-propil ou isopropil) aminoetilalquil (metil, etil, $n$-propil ou isopropil) fosfonitos de $\mathrm{O}$-alquila ( $\mathrm{H}$ ou $\leq \mathrm{C} 10$, incluindo cicloalquila) e sais alquilados ou protonados correspondentes.

Exemplo: QL (O-2-di-isopropilaminoetilmetilfosfonito de O-etila); CAS 57856-11-8.

11) Cloro Sarin: metilfosfonocloridrato de O-isopropila; CAS $1445-76-7$.

12) Cloro Soman: Metilfosfonocloridrato de O-pinacolila; CAS 7040-57-5.

Tabela 2. Substâncias relacionadas na Tabela 2 do anexo sobre substâncias químicas da $\mathrm{CPAQ}^{3}$

\section{Parte A: Substâncias químicas tóxicas}

1) Amiton: Fosforotiolato de O, O-dietil S-[2-(dietilamino) etil]; CAS 78-53-5; e sais alquilados ou protonados correspondentes.

2) PFIB (1,1,3,3,3-pentafluoro-2-(trifluorometil)-1-propeno); CAS 382-21-8.

3) BZ: Benzilato de 3-quinuclidinila; CAS 6581-06-2.

\section{Parte B: Precursores de substâncias químicas tóxicas}

4) Substâncias químicas, com exceção das contidas na Lista 1 , que possuam na sua molécula um átomo de fósforo ligado a um grupo metil, etil, $n$-propil ou isopropil, mas sem mais átomos de carbono.

Exemplos:

- dicloreto de metilfosfonila; CAS 676-97-1;

- dimetilmetilfosfonato; CAS 756-79-6;

Exceção: Fonofos (etilfosfonotiolotionato de O-etil S-fenil); CAS 944-22-9.

5) Di-haletos fosforamídicos N,N-dialquil (metil, etil, n-propil ou isopropil)

6) N,N-diaquil (metil, etil, n-propil ou iso-propil) fosforamidatos dialquílicos (metil, etil, $n$-propil ou isopropil)

7) Tricloreto de arsênio; CAS 7784-34-1 
8) Ácido 2,2-difenil-2-hidroxiacético; CAS 76-93-7.

9) Quinuclidina-3-ol; CAS 1619-34-7.

10) Cloretos de $\mathrm{N}, \mathrm{N}$-dialquil (metil, etil, $n$-propil ou isopropil) aminoetilo-2 e sais protonados correspondentes

11) N,N-dialquil (metil, etil, $n$-propil ou isopropil) aminoetan-2-óis, e os sais protonados correspondentes.

Exceção 1: N,N-dimetilaminoetanol (CAS 108-01-0) e sais protonados correspondentes. Exceção 2: N,N-dietilaminoetanol (CAS 108-37-8) e sais protonados correspondentes.

12) N,N-dialquil (metil, etil, $n$-propil ou isopropil) aminoetanotiol-2 e sais protonados correspondentes

13) Tiodiglicol: Sulfeto de bis(2-hidroxietila); CAS 111-48-8.

14) Álcool pinacolílico: 3,3-Dimetilbutan-2-ol; CAS 464-07-3.

Tabela 3. Substâncias relacionadas na Tabela 3 do anexo sobre substâncias químicas da $\mathrm{CPAQ}^{3}$

\begin{tabular}{|c|}
\hline Parte A: Substâncias químicas tóxicas \\
\hline 1) Fosgênio: dicloreto de carbonila; CAS 75-44-5. \\
\hline 2) Cloreto de cianogênio; CAS 506-77-4. \\
\hline 3) Cianeto de hidrogênio; CAS 74-90-8. \\
\hline 4) Cloropicrina: tricloronitrometano; CAS 76-06-2 \\
\hline Parte B: Precursores de substâncias químicas tóxicas \\
\hline 5)Oxicloreto de fósforo; CAS 10025-87-3. \\
\hline 6) Tricloreto de fósforo; CAS 7719-12-2. \\
\hline 7) Pentacloreto de fósforo; CAS 10026-13-8 \\
\hline 8) Fosfito trimetílico; CAS 121-45-9 \\
\hline 9) Fosfito trietílico; CAS 122-52-1 \\
\hline 10) Fosfito dimetílico; CAS 868-85-9 \\
\hline 11) Fosfito dietílico; CAS 762-04-9 \\
\hline 12) Monocloreto de enxofre; CAS 10025-67-9 \\
\hline 13) Dicloreto de enxofre; CAS 10545-99-0 \\
\hline 14) Cloreto de tionila; CAS 7719-09-7 \\
\hline
\end{tabular}


15) Etildietanolamina; CAS 339-87-7

16) Metildietanolamina; CAS 105-59-9

17) Trietanolamina; CAS 102-71-6

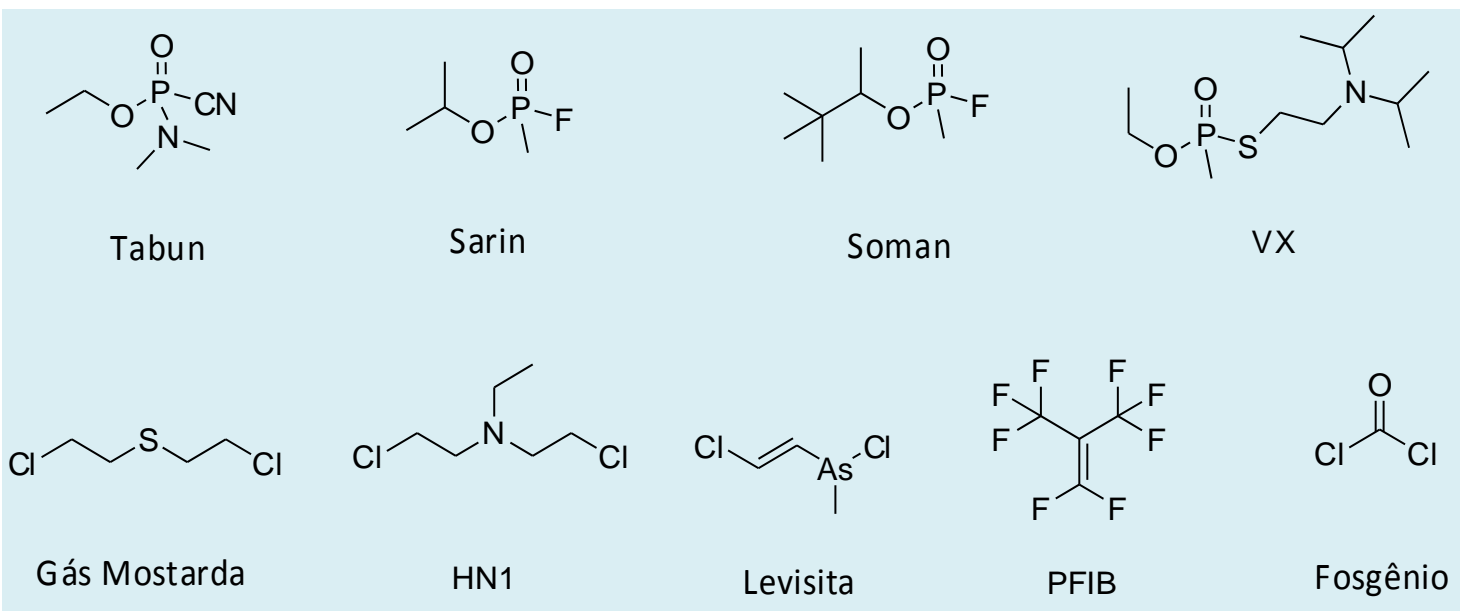

Figura 1. Estruturas moleculares de algumas armas químicas relacionadas no Anexo sobre substâncias químicas da $\mathrm{CPAQ}^{3}$

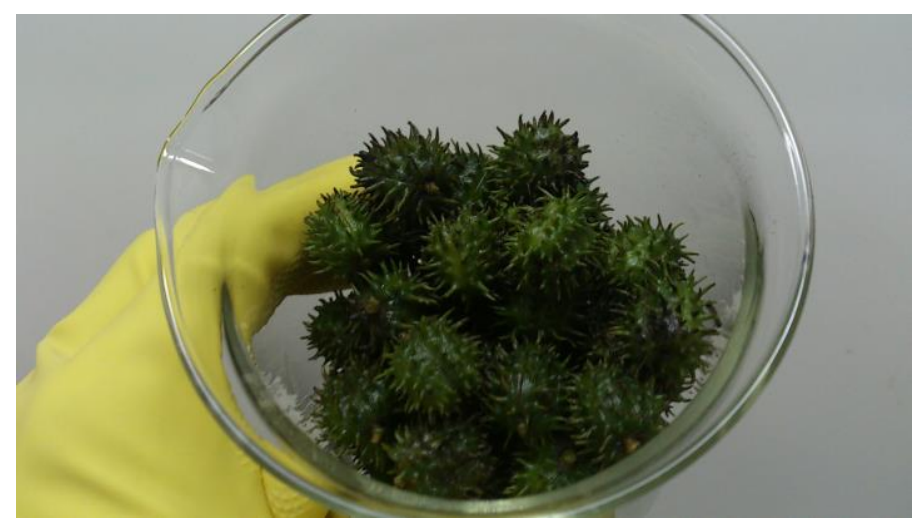

Figura 2. Mamonas colhidas em um terreno em área urbana no Brasil 


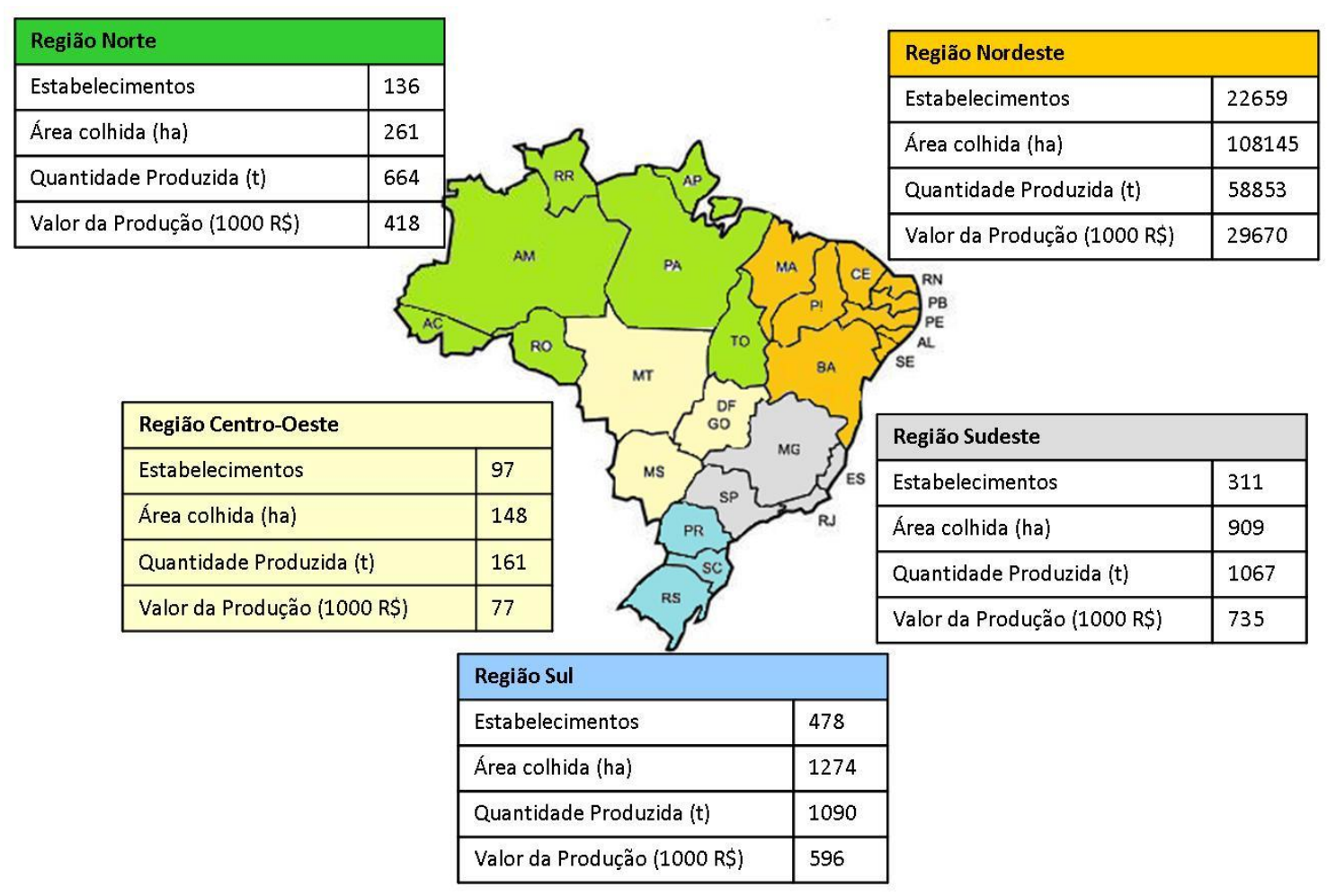

Figura 3. Produção de mamona por região do Brasil, de acordo com o censo agropecuário de $2006^{16}$

\section{Extração de ricina a partir de mamona}

A extração da ricina representa um grande risco à saúde, principalmente se realizada por pessoa sem treinamento e sem utilização de equipamentos de proteção e laboratórios adequados. ${ }^{19}$ Além disso, as legislações brasileiras e internacionais restringem a produção, o armazenamento e o uso dessa toxina. ${ }^{3,5,6} \mathrm{O}$ procedimento de extração de ricina a partir de mamona consiste em uma sequência de processos simples de separação das sementes, moagem, extração por solvente, filtração e secagem. De modo geral, pode ser resumido em quatro etapas, conforme mostrado no fluxograma da Figura 4. ${ }^{19-21}$

Diferenças nos processos de extração e nas etapas de purificação podem resultar em produtos com diferentes graus de pureza. Wunschel e colaboradores utilizaram métodos analíticos de cromatografia gasosa acoplada a espectrometria de massas (CGEM) e análise multivariada de dados para estudar a variação de componentes de amostras de ricina preparadas por diferentes métodos. $^{21}$ Dessa forma, conseguiram estabelecer relações entre as composições das amostras e os métodos de extração utilizados. As variações nas quantidades de manose, arabinose, fucose, ácido ricinoleico e acetona foram importantes fatores de diferenciação. ${ }^{21}$ 


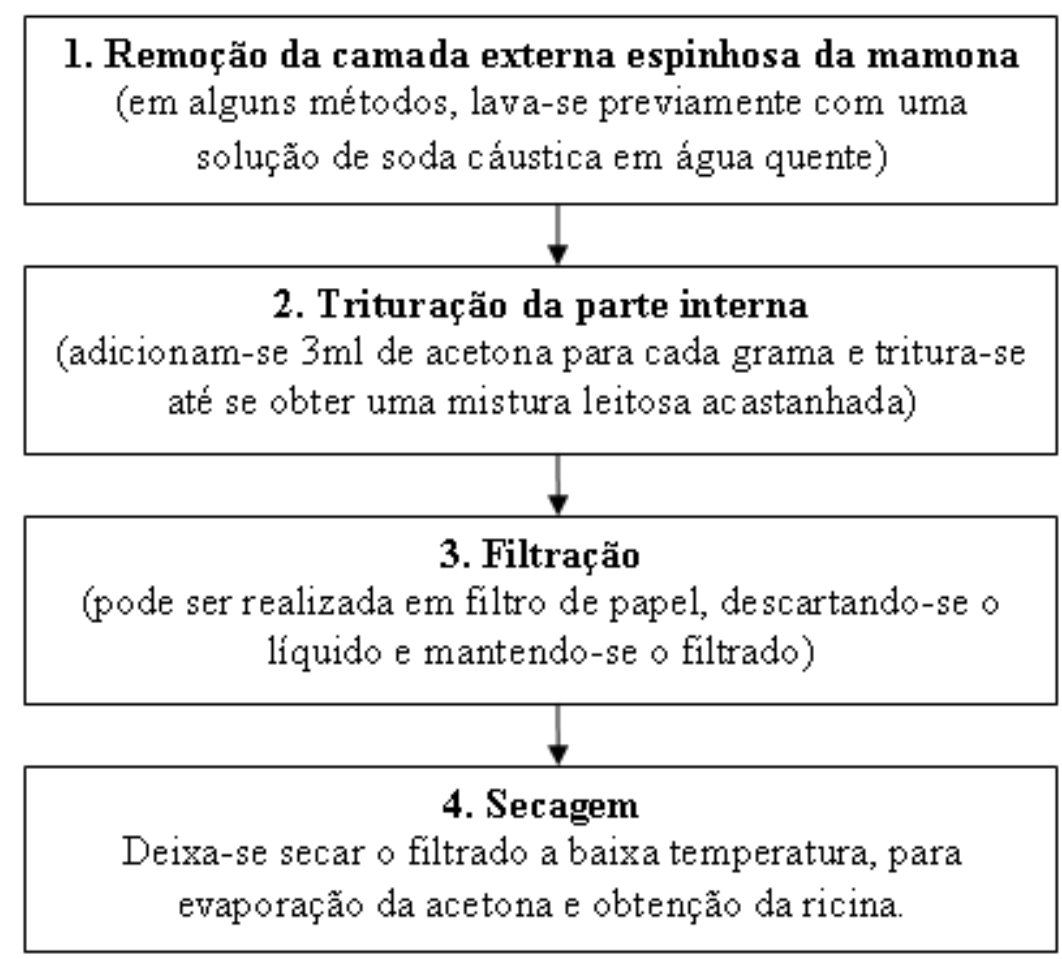

Figura 4. Fluxograma geral do processo de extração da ricina

\section{Estrutura e mecanismo de ação da ricina}

A toxina ricina é uma proteína glicosilada. ${ }^{13}$ Sua sequência de aminoácidos foi determinada por Funatsu e colaboradores $^{22}$ em 1979. Porém, sua estrutura somente foi elucidada em 1991, por Robertus. ${ }^{23,24}$ A Figura 5 mostra a estrutura tridimensional da ricina (adaptada do Protein Data Bank, ID 2AA1). ${ }^{24,25}$ Ela é composta por duas cadeias diferentes " $A$ " e "B" unidas por uma ligação dissulfeto. ${ }^{13,23-26}$ As cadeias A e B possuem, respectivamente, cerca de 32 e $34 \mathrm{kDa}^{19}$ Devido a seu mecanismo de ação no organismo, é classificada como uma proteína inativadora de ribossomos (RIP). ${ }^{19,26} A$ cadeia "B" é uma lectina responsável pela ligação da ricina com os carboidratos da superfície celular. Isso possibilita o processo de endocitose, que conduz a toxina até o interior da célula. A cadeia " $A$ " é uma $\mathrm{N}$-glicosidase e, uma vez dentro da célula, reage especificamente com o RNA ribossômico (rRNA) 28S, provocando a remoção de uma adenina da posição 4324 . A perda de adenina (depurinação) do RNA ribossômico inibe o processo de síntese de proteínas da célula. ${ }^{13,14,19,26,27}$ Uma explicação ricamente ilustrada do mecanismo de ação pode ser encontrada no trabalho publicado por Audi e colaboradores. ${ }^{14}$ 


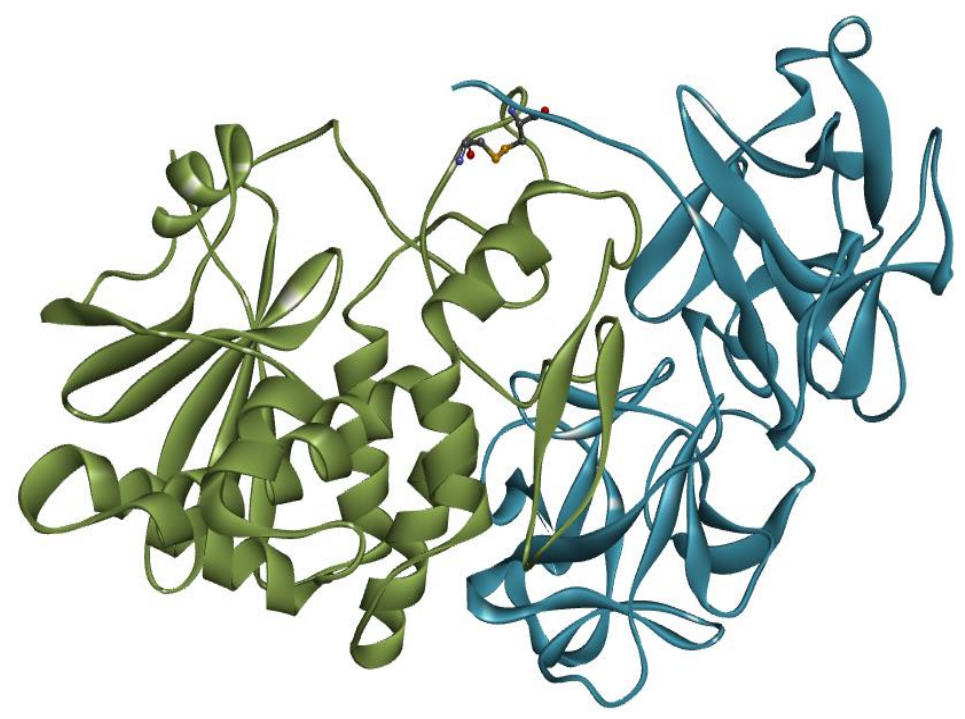

Figura 5. Estrutura tridimensional da ricina. A cadeia $A$ é mostrada em verde e a cadeia $B$ é mostrada em azul. A ponte dissulfeto que une as duas cadeias é representada em bolas e traços (adaptada do Protein Data Bank, ID 2AA1) 24,25

\section{Uso de ricina como arma química}

A grande disponibilidade de mamoneiras no território brasileiro causa preocupação quanto à possibilidade de intoxicações acidentais e quanto ao uso da ricina em atentados terroristas ou em outras ações criminosas.

Diversos casos no exterior já foram relatados sobre o uso indevido dessa toxina. Um dos mais recentes ocorreu em abril de 2013 nos EUA, quando autoridades daquele país interceptaram cartas contendo ricina enviadas ao Senado e à Presidência da República. ${ }^{28}$ Caso semelhante já havia ocorrido nos EUA em novembro de 2003, também sem que as cartas chegassem ao seu destino. ${ }^{14,28}$ Ainda nos EUA, em fevereiro de 2004, um prédio de escritórios usado por senadores americanos chegou a ser fechado e dezenas de funcionários foram submetidos a um processo de descontaminação devido à descoberta de ricina na correspondência. ${ }^{14,28}$ Outro caso famoso envolvendo essa toxina ocorreu em Londres em 1978, ainda no período da Guerra Fria. O jornalista e dissidente político búlgaro Georgi Markov foi levemente atingido em um ponto de ônibus por um minúsculo objeto disparado aparentemente de um guarda-chuva de um transeunte. Mais tarde verificou-se que ele havia sido atingido por um microprojétil contendo ricina, o que causou seu falecimento poucos dias depois. ${ }^{13,14,28,29}$

\section{Detecção e identificação de ricina}

Os métodos mais comumente usados para detecção de ricina são baseados em reações entre anticorpos e antígenos (imunoensaios, como por exemplo, o método ELISA - do inglês "enzime-linked immunosorbent assay") ou em bioensaios nos quais é medida a inativação de um substrato de RNA. ${ }^{30-34}$ Tais métodos estão presentes em alguns equipamentos usados por equipes de resposta a emergências. Entretanto, podem resultar em falsos positivos e falsos negativos, pois não são baseados na identificação inequívoca da molécula da toxina. 
Outras técnicas também utilizadas são eletroforese em gel, reação em cadeia da polimerase em tempo real (RTQ-PCR, do inglês "Real Time Quantitative - Polymerase Chain Reaction") e análises toxicológicas em cobaias. ${ }^{18,35-37}$

Técnicas analíticas que permitem a identificação de sequências de aminoácidos de proteínas ajudam a minimizar a possibilidade de falsos resultados. Dentre elas, a espectrometria de massas com métodos suaves de ionização, tais como: ionização por eletrospray (ESI) e dessorção/ionização a laser auxiliada por matriz (MALDI), têm sido indicadas na identificação de proteínas de alto peso molecular ${ }^{38-45}$.

Schieltz e colaboradores ${ }^{42}$ utilizaram um espectrômetro de massas com ionização por MALDI e analisador por tempo de voo (MALDI/TOF) para identificar a presença de ricina em amostras de um pó branco. A técnica apresentou alta seletividade e sensibilidade. Anticorpos específicos foram usados para extrair a ricina seletivamente de misturas complexas e promover a reação dela com um substrato de RNA, sendo o produto analisado em seguida. ${ }^{42}$

$\mathrm{Na}$ e colaboradores ${ }^{43}$ também utilizaram MALDI/TOF para analisar uma mistura de duas isoformas de ricina intactas que tinham a mesma cadeia B, mas diferentes cadeias A. Os pesquisadores obtiveram sucesso na separação e identificação das diferentes cadeias. $^{43}$

Cromatografia líquida acoplada a espectrometria de massas sequencial (CLEM/EM) com ionização por eletrospray foi utilizada por Östin e colaboradores ${ }^{38}$ para distinguir ricina de outras proteínas semelhantes. A diferença entre os peptídeos da cadeia B da ricina e da cadeia B da proteína RCA120 é de apenas um aminoácido na posição 543 (a cadeia $B$ da ricina possui uma serina, enquanto a cadeia B da RCA120 possui uma asparagina). Apesar da semelhança, os diferentes espectros de massas obtidos possibilitaram a identificação de cada um dos peptídeos. ${ }^{38}$
As análises de identificação da molécula intacta de ricina envolvem as dificuldades típicas das análises de proteínas. Uma alternativa para isso é a tentativa de identificação de um biomarcador mais fácil de ser analisado. Em casos em que se tenta verificar a exposição de um indivíduo à ricina, o biomarcador que pode ser utilizado é a ricinina ou 3-ciano-4-metoxi-N-metil-2piridona (Figura 6). ${ }^{46,47,48} \mathrm{~A}$ ricinina é um alcaloide encontrado na mamoneira e está presente como impureza em amostras de ricina. ${ }^{46,47,48}$

Leite et $a l^{46}$ utilizaram técnicas de cromatografia contracorrente (CCC) para isolar e purificar ricinina do extrato diclorometânico de folhas de Ricinus communis.

Johnson e colaboradores ${ }^{47}$ desenvolveram um método de identificação da ricinina por CL-EM/EM e o aplicaram em estudos com ratos e análises forenses. Concluíram que a ricinina pode ser encontrada na urina de ratos 48 horas depois da exposição à ricina. Posteriormente, em outro trabalho, ${ }^{48}$ o método foi adaptado e testado na análise de 989 amostras de urina humana. Foram detectados 12 resultados positivos $(1,2 \%$ do total) para ricinina. ${ }^{48}$ Tal fato indicou que os resultados desse método não indicam necessariamente uma exposição a ricina, mas devem ser analisados em conjunto com outros fatores, tais como sintomas, contexto, contato com outros produtos que contenham óleo de mamona na composição, etc. ${ }^{48}$<smiles>COc1ccn(C)c(=O)c1C#N</smiles>

Figura 6. Estrutura da ricinina

\section{Descontaminação}

O processo de descontaminação externa 
de pessoas expostas a ricina consiste apenas na remoção das roupas, seguida por lavagem da pele com água corrente. ${ }^{49} \mathrm{Em}$ casos de ingestão, o paciente deve ser submetido imediatamente a um tratamento de lavagem gastrointestinal. ${ }^{49,50}$

\section{Destoxificação}

A torta de mamona possui alto valor nutritivo, com cerca de $42 \%$ de proteínas e $20 \%$ de fibras em sua composição. Além disso, é rica em N, P e K. Entretanto, a falta de um processo de destoxificação de ricina seguro e de baixo custo dificulta o emprego desse produto como ração animal. Diversos estudos têm sido realizados na tentativa de solucionar esse problema, sem, contudo, apresentar uma solução definitiva satisfatória. ${ }^{17,18,51}$

Anandan e colaboradores ${ }^{18}$ estudaram o efeito de diferentes tratamentos físicos e químicos sobre a destoxificação de ricina na torta de mamona. Os melhores resultados foram alcançados com autoclavagem e tratamento com óxido de cálcio $(\mathrm{CaO}) .{ }^{18}$ Contudo, os métodos estudados demandam tempo, energia e custos altos, sem garantia de destoxificação total. A estimativa do teor de ricina utilizou um método desenvolvido em 1947 por Kabat e colaboradores e modificado por Waller e Negi em 1958, baseado em análises de eletroforese em gel (SDS-PAGE, do inglês "Sodium Dodecyl Sulphate Polyacrilamide Gel Electrophoresis"). ${ }^{18,52,53}$

Godoy e colaboradores propuseram o crescimento do fungo Penicillium simplicissimum como forma de destoxificação da ricina por Fermentação em Estado Sólido (SSF). ${ }^{35}$ Apesar dos bons resultados nos testes com células in vitro, a técnica de cromatografia em gel utilizada na estimativa dos teores de ricina não se mostrou totalmente adequada e satisfatória.

Haigler e colaboradores ${ }^{54}$ submeteram ricina à radiação ionizante com a finalidade de estudar a transmissão de energia destrutiva através de ligações dissulfetos de moléculas de proteínas e polímeros. Embora os resultados indiquem mudança na atividade enzimática em função da dose de radiação, eles não se aprofundaram quanto à identificação dos radiólitos formados. Além disso, como não era o objetivo do trabalho, deixaram de avaliar a possibilidade do desenvolvimento de um método de destoxificação por radiação ionizante.

Os métodos de destoxificação propostos até o momento para a torta de mamona demandam tempo, energia, custos e não garantem a destruição total da ricina sem formação de outros produtos tóxicos. As análises são baseadas em toxicidade oral e outros experimentos com animais, que podem ser influenciadas por diversos fatores, como espécie, idade, duração da alimentação, etc. As técnicas mais modernas para análises de identificação e quantificação dos produtos formados após o processo de destoxificação têm sido pouco empregadas nesses estudos. ${ }^{17,18,51}$

\section{Antídotos e vacinas}

Ainda não há um antídoto específico para envenenamento por ricina, tampouco vacina autorizada e disponível comercialmente. A pequena probabilidade de um ataque com ricina em larga escala torna pequeno o interesse na imunização de um grande grupo populacional. Porém, o assunto interessa principalmente aos profissionais de equipes de resposta a emergências e militares sujeitos a combate em ambiente de guerra química e biológica. Diversos trabalhos foram realizados na última década na tentativa de se desenvolver uma vacina, incluindo testes com humanos. Os resultados têm sido promissores e uma empresa norte-americana aguarda aprovação dos órgãos de saúde daquele país para comercialização do produto. ${ }^{12,27,49,50,55,56}$ 


\section{Conclusões}

Os mecanismos de verificação e de destruição de armas químicas previstos na $\mathrm{CPAQ}^{3}$ geraram a necessidade de conhecer os agentes químicos de guerra, seus precursores e produtos de degradação; de detectá-los em diferentes meios; de desenvolver métodos de proteção, de identificação, de descontaminação e de destoxificação.

Dentre as substâncias químicas relacionadas na $C P A Q,{ }^{3}$ a ricina representa elevado risco, devido a sua alta toxidez, grande disponibilidade de mamoneiras no Brasil e facilidade de extração. Por se tratar de um pó branco, pode ser visualmente confundido com diversos outros produtos, dificultando uma identificação rápida. Além disso, essa semelhança pode ajudar a disseminar pânico na população, pois em um caso hipotético de um suposto ataque, qualquer pó branco encontrado passa a ser uma potencial ameaça.

Assim sendo, a rápida detecção e identificação inequívoca das substâncias presentes numa amostra é um fator determinante para o gerenciamento de um caso de suspeita de ataque com armas químicas. Equipes de resposta a emergências têm utilizado métodos de detecção baseados em RTQ-PCR e ELISA. Para confirmação inequívoca em laboratório, MALDI/TOF e CLEM/EM com ionização por eletrospray (ESI) têm sido usados com sucesso na identificação de ricina em matrizes complexas, apresentando alta sensibilidade. Uma alternativa para facilitar as análises tem sido a identificação de ricinina como biomarcador para investigar casos de exposição à ricina.

Os métodos de destoxificação de ricina possuem importância tanto quanto ao aspecto de segurança e defesa, quanto ao aspecto econômico. O primeiro caso está relacionado à importância da descontaminação e destoxificação de locais, materiais e pessoal após um ataque. No campo econômico, pode-se citar o potencial da ampla utilização de torta de mamona detoxificada como ração animal, agregandose valor a um subproduto da agroindústria de óleo de mamona.

Os estudos referentes ao desenvolvimento de uma vacina para imunização contra ricina apresentam resultados promissores, mas ainda não foram suficientes para permitir um produto autorizado comercialmente.

Em conclusão, apesar de seu histórico pacífico, o Brasil não pode desprezar o risco causado pelas armas químicas em seu território. Além de possuir uma gigantesca indústria química, produzindo diversas substâncias tabeladas na CPAQ, deve-se atentar também para o fato de que o país é o terceiro maior produtor de mamonas no mundo. Consequentemente, responsável pela produção de toneladas de ricina, uma das toxinas mais letais existentes. Para combater a vulnerabilidade do possível acesso indevido a armas químicas, cabe ao país não só implantar métodos de verificação e controle, mas também incentivar ainda mais o desenvolvimento de pesquisas, estudos e projetos em busca de maior conhecimento nessa área.

\section{Agradecimentos}

Os autores agradecem ao Departamento de Ciência e Tecnologia (DCT) do Exército Brasileiro, ao Centro Tecnológico do Exército (CTEx) e ao Instituto Militar de Engenharia (IME) pelo apoio oferecido.

\section{Referências Bibliográficas}

${ }^{1}$ Sítio da Organização para a Proibição de Armas Químicas. Disponível em: <http://www.opcw.org >. Acesso em: 9 janeiro 2014.

${ }^{2}$ Sítio do Prêmio Nobel. Disponível em: <http://www.nobelprize.org/nobel prizes/pe ace/laureates/2013>. Acesso em: 09 janeiro 2014. 
${ }^{3}$ OPCW. Convention on the Prohibition of the Development, Production, Stockpiling, and Use of Chemical Weapons and on their Destruction. Organization for the Prohibition of Chemical Weapons. The Hague, 2005. [Link]

${ }^{4}$ OPCW. Statement by José Mauricio Bustani Director-General of the OPCW to the first committee of the United Nations General Assembly. New York, 16 October 1997. [Link]

${ }^{5}$ BRASIL. Decreto Legislativo № 9, de 29 de fevereiro de 1996. Aprova o texto da CPAQ. Diário Oficial da República Federativa do Brasil, Brasília 45, 3701, Seção 1, 6 de março de 1996. [Link]

${ }^{6}$ BRASIL. Decreto da Presidência da República № 2.977 , de $1^{\circ}$ de março de 1999. Promulga a Convenção Internacional sobre a Proibição do Desenvolvimento, Produção, Estocagem e Uso de Armas Químicas e sobre a Destruição das Armas Químicas Existentes no Mundo. Diário Oficial da República Federativa do Brasil, Brasília, 02 de março de 1999. [Link]

${ }^{7}$ Ilha, C.E.G.; A Convenção para a Proibição de Armas Químicas e algumas de suas repercussões para a mobilização pelo Exército Brasileiro. Dissertação de Mestrado, Escola de Comando e Estado-Maior do Exército, 2004. [Link]

${ }^{8}$ Associação Brasileira das Indústrias Químicas (ABIQUIM). Anuário da Indústria Química Brasileira. São Paulo, 2012. [Link]

${ }^{9}$ Associação Brasileira das Indústrias Químicas (ABIQUIM). Guia da Indústria Química Brasileira. São Paulo, 2012. [Link]

${ }^{10}$ Pardasani, D.; Palit, M.; Gupta, A. K.; Kanaujia, P. K.; Dubey, D. K. Gas chromatography-mass spectrometry analysis of trifluoroacetyl derivatives of precursors of nitrogen and sulfur mustards for verification of Chemical Weapons Convention. Journal of Chromatography A 2004, 1059, 157. [CrossRef] [PubMed]

${ }^{11}$ OPCW. Report of the OPCW on the implementation of the Convention on the Prohibition of the Development, Production,
Stockpiling and Use of Chemical Weapons and on their Destruction in 2011. Organization for the Prohibition of Chemical Weapons. The Hague, 2012. [Link]

12 Doan, L. G. Ricin, Mechanism of toxicity, clinical manifestations, and vaccine development. A review. Journal of Clinical Toxicology 2004, 42, 201. [CrossRef]

${ }^{13}$ Olsnes, S. The history of ricin, abrin and related toxins. Toxicon 2004, 44, 361. [CrossRef] [PubMed]

${ }^{14}$ Audi, J. M.; Belson, M.; Patel, M.; Schier, J.; Osterloh, J. Ricin poisoning: A comprehensive review. Journal of American Medical Association 2005, 294, 2342. [CrossRef] [PubMed]

${ }^{15}$ Mutlu, H.; Meier, M. A. R. Castor oil as a renewable resource for the chemical industry. European Journal of Lipid Science and Technology 2010, 112, 10. [CrossRef]

${ }^{16}$ IBGE. Censo Agropecuário 2006 - Brasil, grandes regiões e unidades da Federação. Instituto Brasileiro de Geografia e Estatística, Rio de Janeiro, 2009. [Link]

17 Oliveira, A. S.; Campos, J. M. S.; Oliveira, M. R. C.; Brito, A. F.; Valadares Filho, S. C.; Detmann, E.; Valadares, R. F. D.; de Souza, S. M.; Machado, O. L. T. Nutrient digestibility, nitrogen metabolism and hepatic function of sheep fed diets containing solvent or expeller castor seed meal treated with calcium hydroxide. Animal Feed Science and Technology 2010, 158, 15. [CrossRef]

${ }^{18}$ Anandan, S.; Anil Kumar, G. K.; Ghosh, J.; Ramachandra, K. S. Effect of different physical and chemical treatments on detoxification of ricin in castor cake. Animal Feed Science And Technology 2005, 120, 159. [CrossRef]

${ }^{19}$ Kataoka, M. K.; Kato, H.; Uzawa, H.; Ohta, S.; Takei, Y.; Furuno, M.; Seto, Y. Determination of ricin by nano LC/MS after extraction using lactose-immobilized monolithic silica spin column. Journal of Mass Spectrometry 2011, 46, 821. [CrossRef] [PubMed]

Rev. Virtual Quim. |Vol 6| |No. 3| |744-760| 
${ }^{20}$ Johnson, R. C.; Lemire, S. W.; Woolfitt, A. R.; Ospina, M.; Preston, K. P.; Olson, C. T.; Barr, J. R. Quantification of ricinine in rat and human urine: a biomarker for ricin exposure. Journal of Analytical Toxicology 2005, 29, 149. [CrossRef] [PubMed]

${ }^{21}$ Wunschel, D. S.; Melville, A. M.; Ehrhardt, C. J.; Colburn, H. A.; Victry, K. D.; Antolick, K. C.; Wahl, J. H.; Wahla, K. L. Integration of gas chromatography mass spectrometry methods for differentiating ricin preparation methods. Analyst 2012, 137, 2077. [CrossRef] [PubMed]

${ }^{22}$ Funatsu, G.; Kimura, M.; Funatsu, M. Primary structure of A-chain of ricin $D$. Agricultural and Biological Chemistry 1979, 43, 2221. [CrossRef]

${ }^{23}$ Robertus, J. The structure and action of ricin, a cytotoxic N-glycosidase. Seminars in Cell Biology 1991, 2, 23. [PubMed]

${ }^{24}$ Rutenber, E.; Katzin, B. J.; Ernst, S.; Collins, E. J.; Mlsna, D.; Ready, M. P.; Robertus, J. D. Crystallographic refinement of ricin to $2.5 \mathrm{~A}$. Proteins 1991, 10, 240. [PubMed]

${ }^{25}$ Berman, H. M.; Westbrook, J.; Feng, Z.; Gilliland, G.; Bhat, T. N.; Weissig, H.; Shindyalov, I. N.; Bourne, P. E. The Protein Data Bank. Nucleic Acids Research 2000, 28 , 235. [CrossRef] [PubMed]

${ }^{26}$ Olsnes, S.; Kozlov, J. V. Ricin. Toxicon 2001, 39, 1723. [CrossRef]

${ }^{27}$ Pincus, S. H.; Smallshaw, J. E.; Song, K.; Berry, J.; Vitetta, E. S. Passive and active vaccination strategies to prevent ricin poisoning. Toxins 2011, 3, 1163. [CrossRef] [PubMed]

${ }^{28}$ Hayden, E. C. The quick facts about ricin. Nature News, Apr 17, 2013. [CrossRef]

${ }^{29}$ Schep, L .J.; Temple, W. A.; Butt, G. A.; Beasley, M. D. Ricin as a weapon of mass terror - separating fact from fiction. Environment International 2009, 35, 1267. [CrossRef] [PubMed]

${ }^{30}$ Leith, A. G.; Griffiths, G. D.; Green, M. A. Quantification of ricin toxin using a highly sensitive enzyme-linked immunosorbent assay. Journal of Forensic Sciences 1988, 28, 227. [CrossRef]

${ }^{31}$ Poli, M. A.; Rivera, V. R.; Hewetson, J. F.; Merrill, G. A. Detection of ricin by colorimetric and chemiluminescence ELISA. Toxicon 1994, 32, 1371. [CrossRef]

${ }^{32}$ Shyu, H. F.; Chiao, D. J.; Lu, H. W.; Tang, S. S. Monoclonal antibodybased enzyme immunoassay for detection of ricin. Hybridomics 2002, 21, 69. [CrossRef] [PubMed]

${ }^{33}$ Hines, H. B.; Brueggemann, E. E.; Hale, M. L. HPLC-MS detection assay for adenine released from a synthetic RNA substrate by ricin A chain. Analytical Biochemistry 2004, 330, 119. [CrossRef] [PubMed]

${ }^{34}$ Sturm, M. B.; Schramm, V. L. Detecting ricin: sensitive luminescent assay for ricin $A$ chain ribosome depurination kinetics. Analytical Chemistry 2009, 81, 2847. [CrossRef] [PubMed]

${ }^{35}$ Godoy, M. G.; Fernandes, K. V.; Gutarra, M. L. E.; Melo, E. J. T.; Castro, A. M.; Machado, O. L. T.; Freire, D. M. G. Use of VERO cell line to verify the biodetoxification efficiency of castor bean waste. Process Biochemistry 2012, 47, 578. [CrossRef]

${ }^{36}$ Sehgal, P.; Khan, M.; Kumar, O.; Vijayaraghavan, R. Purification, characterization and toxicity profile of ricin isoforms from castor beans. Food And Chemical Toxicology 2010, 48, 3171. [CrossRef] [PubMed]

${ }^{37}$ Furtado, R. N.; Carneiro, M. S. S.; Cândido, M. J. D.; Gomes, F. H. T.; Pereira, E. S.; Pompeu, R. C. F. F.; Sombra, W. A.; Valor nutritivo de dietas contendo torta de mamona submetida a métodos alternativos de destoxificação para ovinos. Arquivo Brasileiro de Medicina Veterinária e Zootecnia 2012, 64, 155. [Link]

${ }^{38}$ Ostin, A.; Bergstrom, T.; Fredriksson, S. A.; Nilsson, C. Solvent-assisted trypsin digestion of ricin for forensic identification by LC-ESIMS/MS. Analytical Chemistry 2007, 79, 6271. [CrossRef] [PubMed] 
${ }^{39}$ Duriez, E.; Fenaille, F.; Tabet, J. C.; Lamourette, P.; Hilaire, D.; Becher, F.; Ezan, E. Detection of ricin in complex samples by immunocapture and MALDI/TOF-MS. Journal of Proteome Research 2008, 7, 4154. [CrossRef] [PubMed]

40 Brinkworth, C. S.; Pigott, E. J.; Bourne, D. J. Detection of intact ricin in crude and purified extracts from castor beans using MALDI/MS. Analytical Chemistry 2009, 81, 1529. [CrossRef] [PubMed]

41 Brinkworth, C.S. Identification of ricin in crude and purified extracts from castor beans using on-target tryptic digestion and MALDI/MS. Analytical Chemistry 2010, 82, 5246. [CrossRef] [PubMed]

42 Schieltz, D. M; Mcgrath, S. C.; Mcwilliams, L. G; Rees, J.; Bowen, M. D; Kools, J. J.; Dauphin, L. A.; Gomez-Saladin, E.; Newton, B. N.; Stang, H. L.; Vick, M. J.; Thomas, J.; Pirkle, J. L.; Barr, J. R. Analysis of active ricin and castor bean proteins in a ricin preparation, castor bean extract, and surface swabs from a public health investigation. Forensic Science International 2011, 209, 70. [CrossRef] [PubMed]

${ }^{43} \mathrm{Na}$, D. H.; Cho, C. K.; Youn, Y. S.; Choi, Y.; Lee, K. R.; Yoo, S. D.; Lee, K. C. Capillary electrophoresis to characterize ricin and its subunits with matrix-assisted laser desorption/ionization time-of-flight mass spectrometry. Toxicon 2004, 43, 329. [CrossRef] [PubMed]

44 Demirev, P. A.; Fenselau, C. Mass spectrometry in biodefense; Journal of Mass Spectrometry 2008, 43, 1441. [CrossRef] [PubMed]

${ }^{45}$ Herrmann, A.; Rosén, J.; Jansson, D.; Hellenäs, K. E. Evaluation of a generic multianalyte method for detection of $>100$ representative compounds correlated to emergency events in 19 food types by ultrahigh-pressure liquid chromatographytandem mass spectrometry. Journal of Chromatography A 2012, 1235, 115. [CrossRef] [PubMed]
${ }^{46}$ Leite, A. C.; Cabral, E. C.; Santos, D. A. P.; Fernandes, J. B.; Vieira, P. C.; Silva, M. F. G. F. Isolamento do alcaloide ricinina das folhas de Ricinus communis (Euphorbiaceae) através de cromatografias em contracorrente. Química Nova 2005, 28, 983. [CrossRef]

47 Johnson, R. C.; Lemire, S. W.; Woolfitt, A. R.; Ospina, M.; Preston, K. P.; Olson, C. T.; Barr, J. R. Quantification of ricinine in rat and human urine: a biomarker for ricin exposure. Journal of Analytical Toxicology 2005, 29, 149. [CrossRef] [PubMed]

48 Pittman, C. T.; Guido, J. M.; Hamelin, E. I.; Blake, T. A.; Johnson, R. C. Analysis of a ricin biomarker, ricinine, in 989 individual human urine samples. Journal of Analytical Toxicology 2013, 37, 237. [CrossRef] [PubMed]

${ }^{49}$ Spivak, L.; Hendrickson, R. G. Ricin. Critical Care Clinics 2005, 21, 815. [CrossRef] [PubMed]

50 Marconescu, P. S.; Smallshaw, J. E.; Pop, L. M.; Ruback, S. L.; Vitetta, E. S. Intradermal administration of Rivax protects mice from mucosal and systemic ricin intoxication. Vaccine 2010, 28, 5315. [CrossRef] [PubMed]

${ }^{51}$ Dubois, J. L.; Piccirilli, A.; Magneb, J.; He, X. Detoxification of castor meal through reactive seed crushing. Industrial Crops And Products 2013, 43, 194. [CrossRef]

52 Kabat, E. A.; Heidelberger, M.; Bezer, A. E. A study of the purification and properties of ricin. Journal of Biological Chemistry 1947, 168, 629. [PubMed]

${ }^{53}$ Waller, G. R.; Negi, S. S. Isolation of ricin, ricinine, and the allergenic fraction from castor seed pomace from two different sources. Journal of the American Oil Chemist's Society 1958, 35, 409. [CrossRef]

${ }^{54}$ Haigler, H. T.; Woodbury, D. J.; Kempner, E. S. Radiation inactivation of ricin occurs with transfer of destructive energy across a disulfide bridge. Biophysics 1985, 82, 5357. [PubMed]

${ }^{55}$ Smallshaw, J. E.; Richardson, J. A.; Vitetta, E. S. Rivax, A recombinant ricin subunit 
vaccine, protects mice against ricin delivered by gavage or aerosol. Vaccine 2007, 25, 7459. [CrossRef] [PubMed]

${ }^{56}$ Vitetta, E. S.; Smallshaw, J. E.; Coleman, E.; Jafri, H.; Foster, C.; Munford, R.; Schindler, J.
A pilot clinical trial of a recombinant ricin vaccine in normal humans. Proceedings of the Natural. Academy of Sciences 2006, 103, 2268. [CrossRef] [PubMed] 